\title{
2015 update of the evidence base: World Allergy Organization anaphylaxis guidelines
}

\author{
F. Estelle R. Simons ${ }^{1 *}$, Motohiro Ebisawa ${ }^{2}$, Mario Sanchez-Borges ${ }^{3}$, Bernard Y. Thong ${ }^{4}$, Margitta Worm ${ }^{5}$, \\ Luciana Kase Tanno ${ }^{6}$, Richard F. Lockey ${ }^{7}$, Yehia M. El-Gamal ${ }^{8}$, Simon GA Brown ${ }^{9}$, Hae-Sim Park ${ }^{10}$ \\ and Aziz Sheikh ${ }^{11}$
}

\begin{abstract}
The World Allergy Organization (WAO) Guidelines for the assessment and management of anaphylaxis provide a unique global perspective on this increasingly common, potentially life-threatening disease. Recommendations made in the original WAO Anaphylaxis Guidelines remain clinically valid and relevant, and are a widely accessed and frequently cited resource. In this 2015 update of the evidence supporting recommendations in the Guidelines, new information based on anaphylaxis publications from January 2014 through mid- 2015 is summarized. Advances in epidemiology, diagnosis, and management in healthcare and community settings are highlighted. Additionally, new information about patient factors that increase the risk of severe and/or fatal anaphylaxis and patient co-factors that amplify anaphylactic episodes is presented and new information about anaphylaxis triggers and confirmation of triggers to facilitate specific trigger avoidance and immunomodulation is reviewed. The update includes tables summarizing important advances in anaphylaxis research.
\end{abstract}

Keywords: Anaphylaxis, Epinephrine, Auto-injector, Food allergy, Stinging insect venom allergy, Drug allergy, Latex allergy, Exercise-induced anaphylaxis, Systemic allergic reaction, Adrenaline

\section{Introduction}

The World Allergy Organization (WAO) Guidelines for the Assessment and Management of Anaphylaxis remain a clinically relevant, widely accessed, and frequently cited resource [1]. This 2015 Update is intended for use in conjunction with these WAO Anaphylaxis Guidelines, the 2012 and 2013 Updates of the evidence supporting the Guidelines, and the 2014 International Consensus on (ICON): Anaphylaxis, a publication with a broader mandate than the Updates [2-4].

Here, we review research published in peer-reviewed indexed journals from January 2014 through mid-2015 on the epidemiology of anaphylaxis, patient risk factors, amplifying co-factors, triggers, diagnosis, and management in healthcare and community settings. We also highlight excellence in clinical and translational research relevant to anaphylaxis and cite major publications from other

\footnotetext{
* Correspondence: Prof. F.E.R. Simons; contact LMcNiven@exchange.hsc.mb.ca 'Department of Pediatrics \& Child Health and Department of Immunology, College of Medicine, Faculty of Health Sciences, The University of Manitoba, Room FE125, 820 Sherbrook Street, Winnipeg R3A 1R9 MB, Canada Full list of author information is available at the end of the article
}

allergy/immunology professional organizations [5, 6] and different global regions.

\section{Epidemiology}

Updated information about the epidemiology of anaphylaxis, a life-threatening systemic or hypersensitivity reaction with sudden onset, comes from general population surveys and secondary analyses of large clinical and administrative databases [7-16] (Table 1).

The lifetime risk of symptoms suggestive of anaphylaxis in the general population, as reported by members of the public, is at least $1.6 \%$. This estimate is based on a survey of 1000 unselected US adults with a suddenonset illness involving two or more body organ systems, including the respiratory and/or cardiovascular systems, who sensed their lives were in danger and received hospital care [8].

The frequency of hospital admissions for anaphylaxis is increasing. Information obtained from the US Healthcare Cost and Utilization Project Kids' In-Patient Database consisting of a stratified random sample of 12,039,432 hospital discharges indicated that admissions for food- 
Table 1 Epidemiology and patient risk factors

\section{Epidemiology [7-16]}

Hospitalization rates for anaphylaxis continue to increase year-on-year [9-12].

Anaphylaxis fatality rates have remained stable or decreased slightly. Fatalities are age-, co-morbidity-, and trigger-related [12-14].

The highest hospital admission rates for food-induced anaphylaxis occur in very young children age 0-4 years; however, the rate of increase in the age groups 5-14 years and 15-29 years is accelerating [11].

\section{Patient risk factors and amplifying co-factors [17-37]}

Data from an anaphylaxis registry of more than 5000 patients with systemic allergic reactions indicated that although monotherapy with beta-blockers and to a lesser extent, ACE inhibitors, increased the risk of severe anaphylaxis, the risk was further increased by concurrent use of a drug from each class [26].

In an experimental model, although a beta-blocker (metoprolol) given alone had a modestly aggravating effect and an ACE inhibitor (ramipril) given alone had no significant effect, anaphylaxis was exacerbated and mediator release was increased when these medications were given concurrently [26].

In vitro, FccRl-mediated mast cell histamine release was not increased by metoprolol or ramipril given alone, but was synergistically increased when the drugs were given together. This three-part study provides epidemiologic and experimental evidence that ACE inhibitors and beta-blockers aggravate anaphylaxis partly as a result of direct mast cell priming and decreasing the threshold for mast cell activation [26].

In a prospective study of co-factors that amplify anaphylaxis, wheat-dependent, exercise-induced anaphylaxis occurred when plasma gliadin levels were elevated by ingestion of higher gluten doses, gluten and exercise, or gluten and acetylsalicylic acid plus alcohol [36].

ACE angiotensin-converting enzyme inhibitor

induced anaphylaxis in children aged $<18$ years more than doubled from 2000 to 2009 , with corresponding increases in associated healthcare costs [9]. Similarly, analysis of the Italian Ministry of Health database revealed that hospitalizations for food-induced anaphylaxis in children increased year-on-year from 2006 through 2011. The increase was more pronounced in those aged 5-14 years than in those age 4 years or younger [10]. Time trends in Australian hospitalization rates for food-induced anaphylaxis indicate that admissions continue to increase across all age groups. Although the highest hospitalization rates occurred in children age 0-4 years, the greatest acceleration in the rates of increase was found in the age groups 5-14 years and 15-29 years [11].

In England and Wales, hospital admissions from allcause anaphylaxis increased by 615 \% from 1992 to 2012; however, fatalities, checked against a prospective fatal anaphylaxis registry, remained stable at 0.047 cases/ million population. Admission rates and fatality rates for anaphylaxis from drugs and insect stings were highest in the elderly. Admission rates for food-induced anaphylaxis were highest in young people, with a sharp peak in the incidence of food anaphylaxis fatalities in the second and third decades of life [12].
From 1999 to 2009, although hospitalizations for anaphylaxis increased in the USA (annual percentage change $2.2 \%$ ), this contrasted with a decreased case fatality rate among emergency department (ED) patients and hospitalized patients (annual percentage change $-2.35 \%$ ). Overall mortality rates ranged from $0.63-0.76$ /million population (186-225 deaths per year) and appeared stable during the decade studied [13]. In another review of 2458 anaphylaxis fatalities from 1999 to 2010, drugs (58.8 \%) were the most common trigger followed by unspecified inducers (19.3\%), venoms (15.2 \%) and foods $(6.7 \%)$. Fatalities were associated with older age and other demographic factors [14].

Anaphylaxis has been misclassified in both the International Classification of Diseases (ICD)-9 and ICD-10 versions. The global allergy community views the 11th revision, ICD-11, as an opportunity to improve the classification and coding of hypersensitivity/allergic diseases and is aiming to have a specific chapter on these diseases included to facilitate future epidemiological studies $[15,16]$.

\section{Patient risk factors and amplifying co-factors in anaphylaxis}

Many publications now include information on patient risk factors and amplifying co-factors in anaphylaxis [17-37] (Table 1). These risk factors and co-factors differ from one age group to another. They are not yet optimally studied in the pediatric population.

In infancy, there is a paucity of anaphylaxis data because of under-recognition and under-diagnosis due to ageunique symptom patterns. In order to increase awareness of anaphylaxis in this age group, illustrated pathways for clinical diagnosis, management and prevention of recurrences in infants have been developed [19], based on the WAO Guidelines [1].

In teenagers, there is an increased risk of severe and/ or fatal anaphylaxis, as reported in several different types of studies. For example, in those who developed life-threatening anaphylaxis during food oral immunotherapy (OIT) studies, relevant endogenous risk factors included being an adolescent and having uncontrolled asthma, while relevant exogenous co-factors included lack of compliance with asthma preventer medications and/or with OIT protocols, in addition to exercise, fasting, denial of symptoms, and delay in seeking help [20].

In pregnancy, anaphylaxis is uncommon, but potentially catastrophic because it can place mothers and infants at high risk for hypoxic-ischemic encephalopathy or death. Performing skin tests and challenge tests and initiating allergen immunotherapy are typically avoided because of the associated small, although definite, risk of anaphylaxis. A new algorithm for the investigation of anaphylaxis to $\mathrm{RhD}$ immunoglobulin $\mathrm{G}$ (anti-D) has 
been proposed to minimize the need for anti-D challenges in pregnant Rh-negative women. It includes a detailed history, limited skin testing, and fetal Rh genotyping from maternal blood [1, 2, 21].

Old age, combined with co-morbidities such as cardiovascular disease (CVD) and chronic obstructive pulmonary disease, is an important risk factor for severe anaphylaxis with hospitalization, prolonged hospital stay, and fatality $[12,14,17,18,22,23]$. Some widely used life-saving medications for CVD such as beta-blockers and angiotensinconverting enzyme (ACE) inhibitors appear to increase the risk of, or severity of, anaphylaxis; however, their interactions and mechanisms of action are still incompletely understood [23-25].

In a registry involving more than 5000 patients with acute allergic reactions, there was a higher risk of severe anaphylaxis in patients taking a beta-blocker and an ACE inhibitor concurrently than when a beta-blocker or an ACE inhibitor were given alone [26]. These findings were confirmed in an experimental model in which metoprolol given alone had some aggravating effect and ramipril given alone had no significant effect, but anaphylaxis symptoms were exacerbated and mediator release was increased when they were given in combination [26]. In vitro, FceRI-mediated mast cell histamine release was increased by metoprolol and ramipril given together, whereas these substances had no significant effect when given alone; the mechanism likely involved direct mast cell priming and a decrease in the threshold for mast cell activation [26].

Systemic mastocytosis may predispose to severe lifethreatening anaphylaxis. Although many patients with this disorder have few or no mediator-related symptoms, others have recurrent episodes of severe anaphylaxis with clear signs of a mast cell activation syndrome (MCAS). Some patients with systemic mastocytosis have IgE-dependent symptoms; however, the severity and frequency of MCAS reactions do not correlate with specific IgE levels, basal tryptase levels, or the burden of neoplastic mast cells [27]. Other patients have unexplained recurrent episodes of severe anaphylaxis with CVD symptoms such as syncope and elevated basal tryptase levels $(>11.4 \mathrm{mcg} / \mathrm{L})[28]$.

Patients who have indolent systemic mastocytosis (ISM) without skin signs, and anaphylaxis triggered exclusively by insect stings, have clinical and laboratory features that differ significantly from other patients with ISM. In this distinct subgroup, males predominate, basal tryptase levels are not greatly elevated, KIT mutations are frequently restricted to bone marrow mast cells, and there are few bone marrow mast cell aggregates [29].

A rapid inexpensive screening test for the KIT D816V mutation in peripheral blood has been developed. This test facilitated recognition of systemic mastocytosis in 4/113 consecutive adult patients with anaphylaxis who had normal or low basal serum tryptase levels and absent or inconspicuous urticaria pigmentosa skin lesions [30].

More studies on elevation of basal levels of mediators as a risk factor for anaphylaxis are being published. Elevated tryptase levels are found to be a good marker for predicting Hymenoptera venom-induced anaphylaxis [31]. In a controlled study, low basal levels of plateletactivating factor (PAF) acetylhydrolase (leading to increased PAF levels) were also associated with severe venom anaphylaxis [32]. A large extended family with Mendelian inheritance of elevated basal tryptase levels included members with MCAS, anaphylaxis, atopy, and connective tissue abnormalities [33].

Co-factors, including exercise, ethanol, non-steroidal anti-inflammatory drugs (NSAIDs), acute infections, stress, and perimenstrual status potentially amplify anaphylaxis by decreasing the threshold of allergen exposure (the allergen "dose") needed to trigger anaphylaxis and by amplifying the risk of anaphylaxis in patients with low or borderline allergen sensitization [20, 34-37].

The proposed pathophysiologic mechanisms underlying EIA require prospective testing [35]. As an example, in a controlled study in 16 adults with a history of wheatdependent, exercise-induced anaphylaxis (WDEIA) and omega-5-gliadin-specific IgE, prospective oral food challenges (OFCs) with increasing amounts of gluten alone, or in combination with one or more co-factors, were performed until symptoms developed. Plasma gliadin levels were elevated by higher gluten doses, gluten and exercise, or gluten and acetylsalicylic acid (ASA) plus alcohol. Positive plasma gliadin threshold levels differed by more than 100-fold (median $628 \mathrm{pg} / \mathrm{mL}$, range 15-2111). In some patients, exercise was not an essential trigger for symptoms [36].

Perimenstrual anaphylactic episodes in girls and women are attributed to various mechanisms such as hypersensitivity to progesterone or prostaglandin. Estrogen might also play a role by enhancing endothelial expression of nitric oxide synthase and nitric oxide production, increasing vascular permeability, and intensifying anaphylaxis severity [37].

\section{Triggers of anaphylaxis}

Globally important triggers (inducers) of anaphylaxis such as foods, stinging insect venoms, and drugs remain a major research focus [38-77] (Table 2).

In a large European registry study, standardized data are being collected from patients with anaphylaxis referred to allergy/immunology clinics, facilitating accurate comparison of triggers, symptom patterns, and treatment trends across countries [38]. 
Table 2 Food, insect sting, and drug/iatrogenic triggers

Food [34, 38-49]

In a prospective study, 10/12 patients with IgE-mediated mammalian meat-induced systemic allergic reactions had OFCs with meat. Symptom onset occurred in 3-7 hours and correlated with basophil activation and increased CD63 expression, likely reflecting the appearance of galactose-alpha 1,3-galactose (alpha-gal) in the blood. Controls remained asymptomatic after OFCs [45].

Attributed to higher alpha-gal concentrations (or more accessible alpha-gal epitopes), pork kidney elicited symptoms and positive skin tests more consistently than pork muscle meat. Co-factors, including alcohol, NSAIDs, and exercise, amplified low levels of alpha-gal sensitization [34].

Hymenoptera Venom [50-54]

The relevance of asymptomatic sensitization to Hymenoptera venom was tested in 94 people who had previously tolerated field stings without a systemic allergic reaction. On screening, they had elevated venom-specific IgE levels. They underwent a complete evaluation (skin tests, component-resolved diagnosis, BATs, and physician-supervised insect sting challenges). Large local reactions occurred in $43.6 \%$, and systemic reactions occurred in $5.3 \%$. Current venom allergy tests did not distinguish asymptomatic sensitization from risk of local or systemic reactions [52].

The predictive value of in vitro tests with Hymenoptera venoms can be improved by use of recombinant venom allergens and component resolved testing, for example, by utilizing a panel of honeybee allergens that are free from cross-reactive carbohydrate determinants $[53,54]$.

Drugs/latrogenic Agents [55-77]

The health consequences of penicillin "allergy" included costly longer admissions, greater use of broad-spectrum antibiotics, and increased prevalence of serious infections with Clostridium difficile, methicillin-resistant Staphylococcus aureus, and vancomycin-resistant enterococci [58].

Risk factors for fatal anaphylaxis to a neuromuscular blocker included male sex, emergency setting, CVD/hypertension, concurrent beta-blocker treatment, and obesity [71].

Of 228 consecutive patients with perioperative anaphylaxis, $9.6 \%$ were sensitized to the antiseptic/disinfectant chlorhexidine, as determined using specific lgE measurements, basophil activation tests, and standardized skin tests [73].

alpha-gal galactose-alpha 1,3-galactose; BATs basophil activation tests, CVD cardiovascular disease, NSAIDs non-steroidal anti-inflammatory drugs; OFCs oral food challenges

\section{Food-induced anaphylaxis}

The immunopathology of food-induced anaphylaxis, tests to confirm specific triggers, and approaches to management have been reviewed in depth [39, 40]. Foods are by far the most common anaphylaxis trigger in infants, children, teens, and young adults [9-12]. As reported in a meta-analysis of data from 34 studies, the incidence rate of food-induced anaphylaxis was 0.14 per 100 person-years at all ages, and up to 7 per 100 personyears in children aged $0-4$ years [41].

In a retrospective study of 168 adults aged $>18$ years with new-onset food allergy, symptoms typically began in the second and third decades; $49 \%$ of these patients reported anaphylaxis. Shellfish, tree nuts, fish, soy, and peanut accounted for most cases, although many other foods were implicated [42].
A 3 year follow-up study in 80 children with ED visits for systemic allergic reactions (SARs) to foods who had 116 repeat ED visits confirmed that severity of previous reactions did not predict severity of subsequent reactions [43].

In the past two decades, cashew has become an important allergen due to increased consumption. Like other tree nuts and peanuts, it contains potent allergens that can trigger severe anaphylaxis when ingested in trace amounts. Cross-reactivity with pistachio is reported [39, 44].

In a prospective controlled study, 10 of 12 patients with a history of urticaria after ingestion of mammalian meat developed reactions ranging from urticaria to anaphylaxis within 3-7 hours of an open OFC with meat. Basophil activation (increased CD63 expression) correlated with symptom onset, likely reflecting antigen (galactose-alpha 1,3-galactose [alpha-gal]) appearance in the blood. None of the 13 control subjects developed symptoms [45].

In patients with alpha-gal-induced anaphylaxis, pork kidney elicited symptoms and positive skin prick tests (SPT) more consistently than pork muscle meat, attributed to higher alpha-gal concentrations (or more accessible alpha-gal epitopes) in pork kidney compared with muscle. Co-factors, including alcohol, NSAIDs, and exercise amplified low levels of sensitization to alpha-gal [34].

Anaphylaxis has been reported from Japan in patients who ingested okonomiyaki pancakes made from mitecontaminated pancake mix and who had elevated specific IgE to Dermatophagoides and Tyrophagus species [46].

In pharmaceutical formulations and other manufactured products, foods and food derivatives used as excipients include: egg protein, egg lecithin, fish protamine, fish oil, gelatin (bovine or porcine), casein, lactalbumin, lactose, peanut oil, sesame oil, soy lecithin, soy oil, and soy phosphatidylcholine [47]. Anaphylaxis has been reported in children with milk allergy and asthma treated with lactose-containing intravenous (IV) formulation of methylprednisolone sodium succinate [48], and lifethreatening anaphylaxis has been reported after topical exposure to casein in an Everlast kickboxing glove [49].

\section{Insect sting or bite-induced anaphylaxis}

Many people in the general population who have tolerated previous insect stings are sensitized to Hymenoptera venom [50,51]. In a prospective study to test the relevance of asymptomatic sensitization, 94 such individuals had venom skin tests (prick and intradermal), specific IgE levels, component-resolved diagnosis, and basophil activation tests (BATs), followed by physiciansupervised challenge stings from one or more live insects. Large local reactions occurred in $43.6 \%$ (a 9.5-fold 
increased risk versus asymptomatic, unsensitized individuals), and SARs occurred in $5.3 \%$, suggesting that currently available tests cannot distinguish asymptomatic sensitization from the risk of large local reactions or SARs [52].

Patients who are clinically allergic to Hymenoptera venom yet have absent or undetectable venom-specific IgE can be identified by measuring serum IgE to a panel of recombinant honeybee and yellow jacket venom allergens (rVes $\mathrm{v} 1$, rVes $\mathrm{v} 2$, rVes $\mathrm{v} 3$, and rVes $\mathrm{v} 5$, and rApi $\mathrm{m} 1$, rApi $\mathrm{m}$ 2, rApi $\mathrm{m} 3$ and rApi $\mathrm{m}$ 5). Use of recombinant allergens significantly increases test sensitivity, as compared with specific IgE measurements to commercial venom extracts [53].

Improved in vitro tests for patients with honeybee venom allergy are being developed. Analysis of a panel of cross-reactive carbohydrate determinant-free honeybee venom allergens improved diagnostic sensitivity compared with use of rApi $\mathrm{m} 1$ alone, identified additional major allergens, and revealed sensitization to allergens that have been reported to be absent or under-represented in commercial venom extracts [54].

\section{Drug-induced anaphylaxis}

Drugs, most commonly antibiotics, NSAIDs, and neuromuscular blocking agents (NMBAs), are frequent triggers of anaphylaxis. Drug-induced anaphylaxis is underrecognized. It can also be over-diagnosed based on history alone. Allergy/immunology evaluations are underutilized. Immediate reactions occurring within one hour after dosing are typically mediated by specific IgE. Skin testing is validated for beta-lactam antibiotics, but less so for other antibiotics and for other drug classes. Drug provocation tests are useful in selected patients [55-57].

A history of penicillin "allergy" has important health consequences. In a cohort of 51,582 hospitalized US patients versus matched controls, those with a history of penicillin "allergy" had significantly longer admissions, greater use of broad-spectrum antibiotics including fluoroquinolones, clindamycin, and vancomycin, and increased prevalence of serious infections including Clostridium difficile, methicillin-resistant Staphylococcus aureus, and vancomycin-resistant enterococcal infections [58]. In a UK teaching hospital, the total cost of antibiotics prescribed for patients reporting "penicillin allergy" was 1.8 to 2.6-fold higher than for first-line antibiotics [59].

Assessment by history and skin tests can rule out the likelihood of an acute allergic reaction to penicillins in 90-95\% of patients with a history of penicillin allergy, potentially leading to large cost savings in health systems. Skin testing with commercially available benzyl penicilloyl-polylysine (PrePen), previously validated in adults, has now also been validated in children [60].
Physician-documented cephalosporin anaphylaxis is rare. In a large US healthcare system, anaphylaxis occurred during only five oral cephalosporin exposures among 901,908 oral courses and during only eight parenteral cephalosporin exposures among 487,630 parenteral courses [61].

Although many penicillin-allergic patients can tolerate aztreonam or carbapenems, rare cross-reactivity between penicillins and these drugs has been reported. Of 212 consecutive patients with a penicillin allergy history and positive skin tests to one or more penicillins, all had negative skin tests to aztreonam and three carbapenems (imipenem-cilastatin, meropenem, and ertapenem). Of the 211 patients who consented to challenge, all passed. Pre-treatment skin tests with aztreonam and carbapenems are nevertheless still recommended because negative tests indicate tolerability [62].

In contrast, skin tests cannot be relied on to confirm hypersensitivity to quinolones. Drugs such as moxifloxacin frequently produce positive skin test responses in healthy individuals, and testing with high concentrations does not distinguish between patients with a history of reactions and control patients who have been exposed [63].

Few cases of anaphylaxis to macrolide antibiotics such as erythromycin or clarithromycin have been reported to date. Azithromycin-induced anaphylaxis has been confirmed by skin testing in three children [64].

NSAIDs are major triggers of anaphylaxis $[65,66]$. In the Portuguese Pharmacovigilance system, over 4 years, they were responsible for $47.9 \%$ of drug-induced anaphylaxis episodes and $25.6 \%$ of anaphylaxis recurrences. Implicated drugs included preferential COX-1 inhibitors such as ASA, diclofenac, ibuprofen, naproxen, and, uncommonly, weak COX-1 inhibitors such as paracetamol (acetaminophen) [66].

Nine cases of IgE-dependent anaphylaxis to diclofenac were recorded over a decade by the Allergy Vigilance Network in France. Sensitization to diclofenac was confirmed in four of these patients by positive intradermal tests, in one patient who developed acute urticaria after intradermal testing, and in one skin test-negative patient who developed anaphylaxis after an oral challenge with diclofenac. The investigators emphasized the need for development of tests to measure specific IgE to frequently used NSAIDs such as diclofenac and ibuprofen [67].

Administration of any drug by any route can potentially cause anaphylaxis. As an example, $3.5 \%$ of 230 patients developed anaphylaxis within one hour of subcutaneous injection of the plasma kallikrein inhibitor ecallantide. There was no consistent association with IgE to ecallantide or to Pichia pastoris, the yeast cells in which ecallantide is produced by recombinant DNA technology [68]. 
Hypersensitivity reactions ranging from mild skin reactions to life-threatening anaphylaxis from biological agents such as rituximab, trastuzumab, cetuximab, ofatumumab, tocilizumab, and brentuximab are increasing in frequency as use of these potentially life-saving agents increases in neoplastic, auto-immune and inflammatory diseases. Desensitization enables patients to receive a full treatment regimen of these agents without developing anaphylaxis [69].

Perioperative anaphylaxis, a serious complication, is reported in up to $1 / 13,000$ anesthetics. It can be caused by NMBAs such as atracurium, suxamethonium, rocuronium, or vecuronium; or by antibiotics, blood and blood products, dyes, chlorhexidine, or natural rubber latex. In a prospective study, 13 of 4595 ( 1 in 353) patients having a general anesthetic met referral criteria for investigation of perioperative anaphylaxis, suggesting that the problem is under-diagnosed [70]. From 2000 to 2011, 2022 cases of NMBA anaphylaxis, 84 (4.1\%) of which were fatal, were reported to the French National Pharmacovigilance Network. Independent risk factors associated with death were: male gender, emergency setting, history of hypertension or other CVD, ongoing beta-blocker treatment, and obesity [71].

In 14 of 15 patients with perioperative anaphylaxis due to sugammadex injection for reversal of neuromuscular blockade, symptoms began within four minutes of the sugammadex injection [72].

Chlorhexidine, an antiseptic/disinfectant active against a broad spectrum of bacteria, viruses, and fungi, is an increasingly common anaphylaxis trigger found in skin cleansers, central venous lines, urinary catheters, and other products. Chlorhexidine sensitization was identified in $9.6 \%$ of 228 patients with perioperative anaphylaxis by using specific IgE measurements, BAT, and standardized SPT and intradermal tests [73].

Natural rubber latex allergy remains an important anaphylaxis trigger in many countries. In Israel, prospective use of a 9-item written screening questionnaire before elective Caesarean delivery identified potential clinical reactivity to latex in $14.6 \%$ of 453 women, compared with identification of potential reactivity in only $2.6 \%$ of 460 women who answered a standard verbal inquiry [74].

Of 104 patients with iodinated radiocontrast media (RCM)-induced anaphylaxis, 34.6\% developed it on their first RCM exposure. Patients presenting with shock were older and had more frequent RCM exposures. In the 51 patients who were skin tested, the overall positivity rate was $64.7 \%$ and in those with shock, it was $81.8 \%$ [75].

Although gadolinium-based contrast agents are recommended in patients with a history of RCM-induced anaphylaxis, they, too, can trigger anaphylaxis. Of 614 cases reported to the US Food and Drug Administration's Adverse Event Reporting System, 43 \% were associated with gadopentetate dimeglumine, $29 \%$ with gadobenate dimeglumine, and $17 \%$ with gadoteridol [76].

In a case series of anaphylaxis to IV fluorescein, the most common presentation was hypotension, typically occurring within three minutes of dye infusion [77].

\section{Diagnosis of anaphylaxis}

Diagnosis of anaphylaxis depends on recognition of characteristic symptoms and signs that occur minutes to hours after exposure to a known or potential trigger [1]. High-quality studies relevant to clinical diagnosis and laboratory tests to support the diagnosis of anaphylaxis are being published [78-90] (Table 3).

The major anaphylaxis guidelines include the $\mathrm{Na}$ tional Institute of Allergy and Infectious Diseases clinical criteria for diagnosis, a practical instrument for rapid identification of patients with a likely diagnosis of

Table 3 Diagnosis, initial treatment, and self-treatment in community settings

\section{Diagnosis [78-90]}

In a prospective controlled study of ED patients with anaphylaxis, up-regulation of innate inflammatory gene networks was reported. On ED arrival, two genes were expressed; one hour after arrival, 67 genes were expressed; and three hours after arrival, 2801 genes were expressed. Genomic responses provide new insights into the potential release of a cascade of mediators in anaphylaxis [90].

\section{Initial treatment [91-103]}

Early injection of epinephrine in anaphylaxis, defined as initial injection before ED arrival, significantly reduced the likelihood of hospital admission, compared with initial epinephrine injection after ED arrival [92].

Epinephrine was injected before cardiac arrest in only $23 \%$ of 92 individuals who experienced a fatal anaphylaxis episode [93].

In an observational study, data confirmed the safety of IM epinephrine injection, typically given through an epinephrine auto-injector: (adverse events $1 \%$, and no overdoses). In contrast, IV bolus injections were associated with significantly more adverse events (10\%) and overdoses (13\%) [99].

In a systematic review and meta-analysis of 27 studies, $4.7 \%$ of 4114 patients with anaphylaxis had biphasic episodes (range $0.4 \%$ to $23.3 \%$ ). Patients who presented with hypotension or who had an unknown inciting trigger were at increased risk. The data suggested that for patients with anaphylaxis who are treated successfully in an ED, the duration of observation should be risk-stratified according to the clinical characteristics and severity of the episode [101].

\section{Long-term management: self-treatment in community settings} [104-118]

Patients who were treated in an ED for anaphylaxis benefited from referral to $\mathrm{A} / \mathrm{I}$ specialists who clarified the diagnosis and correctly identified and confirmed specific anaphylaxis triggers [104].

Novel EAls are now available in some countries. The compact Auvi-Q can be used correctly on first attempt by $93 \%$ of parents who have never seen or heard it before. The Emerade is available in $0.15 \mathrm{mg}$, $0.3 \mathrm{mg}$, and $0.5 \mathrm{mg}$ doses. The $0.3 \mathrm{mg}$ and the $0.5 \mathrm{mg}$ dose EAls have a $25 \mathrm{~mm}$ long needle. EAls differ significantly with regard to size, ease of carrying, ease of use, needle protection, and robustness. They are not interchangeable [107, 108].

$A / l$ allergy/immunology, $E D$ emergency department, $E A$ l epinephrine autoinjector, $I M$ intramuscular, $I V$ intravenous 
anaphylaxis $[1,5,6,78]$. These criteria are validated for use in EDs and other medical settings and in epidemiological research, in which they are used to define study populations. In order to operationalize them, illustrations $[1,2,19]$ and a color-coded chart [78] have been developed.

Under-diagnosis of anaphylaxis is common. Although over $80 \%$ of 7822 responders (most of whom were physicians or allied healthcare professionals) correctly identified anaphylaxis when given a case scenario of a patient with cutaneous involvement, only $55 \%$ recognized anaphylaxis in a case without cutaneous involvement [79]. Importantly, diagnostic confusion has been reported in children hospitalized for life-threatening asthma, some of whom met diagnostic criteria for anaphylaxis [80].

Less common considerations in the differential diagnosis also need to be kept in mind, as in the following examples: Anaphylaxis due to ruptured hydatid cyst can occur in areas without endemic Echinococcus granulosus, a reminder that untreated patients who have lived in endemic areas remain at life-long risk [81]. Idiopathic systemic capillary leak syndrome has now been documented in children aged 5-11 years; therefore, in the pediatric population, as in adults, it should be considered in the differential diagnosis of anaphylaxis in patients who present with hypotension, shock, and fluid extravasation [82].

In addition, misdiagnosis or over-diagnosis of anaphylaxis can occur, as described in patients with acute multisystem symptoms after ingestion of caustic substances, and those with foreign body inhalation, acute urticaria, or angioedema [83, 84].

\section{Role of laboratory tests}

Serum tryptase levels in blood samples taken 15-180 minutes after symptom onset can support the clinical diagnosis of anaphylaxis in some but not all patients $[1,5,6]$. In food-induced anaphylaxis, single tryptase measurements are typically within the normal reference range; however, in these patients, use of a ratio (peak tryptase level divided by basal level) is reported to improve sensitivity, specificity, and positive and negative likelihood ratios [85].

In perioperative anaphylaxis, serum tryptase levels are not compromised by large volumes of fluid or by resuscitation [86]. An elevated "acute" serum tryptase level (\% change $>141 \%$; or absolute tryptase level of $>15.7 \mathrm{mcg} / \mathrm{L}$ ) has been reported to be highly predictive of IgE-mediated perioperative anaphylaxis in a multi-center, retrospective analysis [87].

In post-mortem sera, serum tryptase levels can vary in the same person depending on the site of blood sampling; moreover, elevated levels are not specific for anaphylaxis, but can also occur in people who die from myocardial infarction, asphyxia, or trauma [88].

Even when tryptase levels are within the normal reference range, other mediators of inflammation such as histamine, PAF, PGD2, and LTE4 can be elevated in anaphylaxis [1-6]. Heparin, the contact system, and activation of factor-XII are also involved in anaphylaxis, generating plasma kallikrein that protealyzes kininogen and leads to bradykinin release; moreover, the intensity of contact system activation and bradykinin formation are associated with anaphylaxis severity [89].

Reliance on elevation of only one mediator of inflammation to confirm the clinical diagnosis of anaphylaxis is likely insufficient. In a prospective controlled study of ED patients with moderately severe anaphylaxis, gene expression in peripheral blood samples was profiled in microarrays, differentially expressed genes were identified, and network analysis was used to explore underlying mechanisms [90].

In these patients, on ED arrival, two genes were differentially expressed. One hour post-arrival, 67 genes were expressed; and three hours post-arrival, 2801 genes were expressed. Network analysis demonstrated up-regulation of three inflammatory modules, each containing multiple hub-genes with a central role in the regulation of innate inflammatory responses [90].

Genomic responses in anaphylaxis provide insight into potential release of a cascade of mediators that might play a role in escalation of anaphylaxis symptoms and signs [90].

\section{Initial treatment of anaphylaxis}

Anaphylaxis is a life-threatening medical emergency in which prompt intervention is critical. Principles of treatment remain unchanged [1]; however, recommendations for treatment are based on evidence of increasingly high quality [91-103] (Table 3).

International guidelines concur that epinephrine (adrenaline) is the medication of first choice in anaphylaxis because it is the only medication that reduces hospitalization and death. Its life-saving alpha-1 agonist vasoconstrictor effects prevent and relieve airway edema, hypotension, and shock; its beta-1 agonist chronotropic and inotropic effects increase the rate and force of cardiac contractions, and its beta- 2 agonist effects lead to bronchodilation and decreased mediator release [1, 5, 6, 78, 91-93].

Early injection of epinephrine in anaphylaxis, defined as injection before ED arrival, can significantly reduce the likelihood of hospital admission, as compared with initial injection after ED arrival [92]. Delayed injection of epinephrine has been reported in yet another large series of anaphylaxis-related fatalities in which only $23 \%$ of the 92 individuals received it before cardiac arrest [93]. Although epinephrine injection rates remain low in many EDs [94], use of protocols or order sets can significantly improve injection rates [95].

Epinephrine is significantly less likely to be injected in food-induced anaphylaxis than in venom-induced 
anaphylaxis [38]. Other reasons for failure to inject it include: not giving it because symptoms appear mild or moderate, or there are perceived contraindications to it (pregnancy, older age, or CVD) [95-97], or the patient refuses it [98]. In fact, there are no absolute contraindications to epinephrine $[1,4-6]$.

More emphasis is needed on prompt recognition and appropriate treatment of anaphylaxis by healthcare professionals. In a 2013 study, although junior doctors' ability to manage anaphylaxis was somewhat improved compared with a similar study in a 2002 physician cohort, only one-third of them knew the correct dose and route for epinephrine administration [84].

In an ED single-center retrospective observational cohort study of epinephrine safety, $58 \%$ of 573 consecutive patients received epinephrine for anaphylaxis. Only four of 316 patients (1\%) who received an intramuscular (IM) epinephrine injection (most doses administered through an auto-injector) developed adverse events; in contrast, three of 30 patients (10\%) who received IV bolus epinephrine had adverse events. There were no overdoses with IM injection, versus an overdose rate of $13 \%$ after IV bolus administration. These data support the safety of the IM route and suggest need for extreme caution when IV bolus doses are administered [99].

International guidelines concur that $\mathrm{H}_{1}$-antihistamines, $\mathrm{H}_{2}$-antihistamines, and glucocorticoids are second-line $[1,6,78]$ or even third-line [5] medications in anaphylaxis. These medications are not life-saving and should not be used as initial or sole treatment. A systematic review of $\mathrm{H}_{2}$-antihistamines in anaphylaxis found no randomized controlled trials (RCTs) that met the criteria for inclusion; the $\mathrm{H}_{2}$-antihistamines had been studied in acute allergic reactions in which skin symptoms predominated; most (80 \%) of the patients had no respiratory or cardiovascular involvement and did not have anaphylaxis [100]. Glucocorticoids are typically administered to prevent biphasic or protracted episodes of anaphylaxis and have little or no effect on initial symptoms and signs $[1,5,6,78]$.

In a systematic review and meta-analysis of 27 observational studies, biphasic episodes occurred in 192 $(4.7 \%)$ of 4114 patients with anaphylaxis (range $0.4 \%$ to $23.3 \%$ ) [101]. Patients with unknown triggers and those presenting with hypotension were at increased risk; those with food-induced anaphylaxis were at decreased risk. These data suggest that routine prolonged monitoring is unnecessary in patients whose anaphylaxis symptoms have resolved and that the duration of observation should be risk-stratified according to the clinical characteristics and severity of the episode [101].

Methylene blue, a selective nitric oxide cyclic GMP inhibitor, prevents vasodilation and can rapidly reverse the course of anaphylaxis refractory to epinephrine, oxygen, and IV fluid resuscitation. Use in anaphylaxis is based on case reports and extrapolated from use in septic shock. Limitations include adverse events and interference with pulse oximetry [102].

In patients with life-threatening anaphylaxis, cardiovascular collapse, and cardiac arrest, extracorporeal membrane oxygenation (ECMO) is reported to act as a bridge to recovery [103].

\section{Long-term management of anaphylaxis in community settings: self-treatment}

Treatment of anaphylaxis does not end with resolution of an acute episode [1]. Aimed at decreasing anaphylaxis morbidity and mortality in community settings, high-quality studies, including prospective studies of epinephrine auto-injectors (EAIs) and of anaphylaxis education, are being published [104-118] (Table 3). Further studies of the long-term benefits of anaphylaxis education are needed.

Allergy/immunology specialists clarified the diagnosis or accurately identified and confirmed the specific anaphylaxis trigger in $35 \%$ of patients referred from an ED after treatment for anaphylaxis [104]. Visits to an allergist/immunologist reduced the risk of severe anaphylaxis requiring hospital admission [17].

In many countries, EAIs are still unavailable [94]. Where they are available, they remain under-prescribed and under-used; as an example, only $11 \%$ of 261 individuals with a history of confirmed anaphylaxis had used an EAI during their most recent episode, and $52 \%$ reported that they had never received an EAI prescription $[8,105]$. In another study, only $16 \%$ of 102 patients could demonstrate the correct use of an EpiPen; most patients made at least one mistake and $56 \%$ of them missed three or more steps [106].

New EAIs are being developed and introduced. In the US and Canada, the Auvi-Q is a user-friendly, uniquelyshaped EAI (not a pen), with audio and visual prompts, and needle protection before and after use [107]. Most parents (93\%) who had never previously seen an Auvi-Q or a demonstration of its use intuitively used it correctly on their first attempt [108]. In Europe, the Emerade is available in a $0.15,0.3$, and $0.5 \mathrm{mg}$ dose, with a $16 \mathrm{~mm}$ needle on the $0.15 \mathrm{mg}$ EAI and a $25 \mathrm{~mm}$ (1-inch needle) needle on the $0.3 \mathrm{mg}$ EAI and the $0.5 \mathrm{mg}$ EAI.

EAIs differ significantly with regard to size, ease of carrying, ease of use, needle protection, and robustness. They are not inter-changeable $[107,108]$.

However, manufacturers' recommendations are similar for all EAIs with regard to storage: keep at $20^{\circ}$ to $25^{\circ} \mathrm{C}$ (excursions permitted from $15^{\circ}$ to $30^{\circ} \mathrm{C}$ ) to protect the epinephrine solution from degradation and ensure mechanical integrity of the device. In a warm climate, the degradation of epinephrine solution in EAIs is potentially accelerated [109]. If EAIs are subjected to 
freezing temperatures for a few days, no degradation of epinephrine solution occurs; however, they must be completely thawed before use [110].

Long-term follow-up is important to ensure retention of skills by patients, caregivers, and healthcare professionals. As an example,160 medical interns had theoretical training about anaphylaxis and practical demonstrations with EpiPen trainers. They were then randomly assigned into one group tested 3 months later and another group tested 6 months later. Test scores and EAI demonstration skills, including mean time to "inject epinephrine" from EpiPen trainers, were retained at 3 months, but decreased significantly at 6 months [111].

Structured education programs improve anaphylaxis management. In a prospective study, 98 patients with a history of anaphylaxis and 95 caregivers received two anaphylaxis education modules, each lasting three hours. At follow-up 3 months later, those receiving this intervention improved significantly in knowledge and competence in emergency management, and caregiver anxiety was reduced, as compared with controls who received only standard auto-injector training [112].

An anaphylaxis e-learning program for pharmacists developed by the Australian Society of Clinical Immunology and Allergy was compared with lectures or no training at all. Effectiveness was measured using a validated test administered pre-training, immediately post-training, and 3 months and 7 months later. The proportion of elearners achieving the minimum standard for anaphylaxis knowledge improved from $45 \%$ at pre-test to $87 \%$ at 7 months, confirming long-term improvement versus comparators [113].

In many US schools, unassigned EAIs are now available for use in or by students who experience anaphylaxis and do not have a personal EAI available. Efforts to reduce disparities in EAI availability within and between school districts are ongoing [114].

Incorporation of prospectively validated pictograms into a pediatric anaphylaxis emergency action plan potentially increases comprehension of triggers, symptoms and signs, and management [115].

A nurse delivered a training program in person to 4818 individuals at 247 schools and community sites. Written evaluations, online surveys, and phone interviews were used to measure effectiveness. In-person training increased participants' knowledge and confidence in prevention, recognition, and treatment of anaphylaxis [116].

In some countries, school staff are reported to have a low level of preparedness to prevent and manage foodinduced allergic reactions [117]. Guidelines outlining a standardized approach to risk management of patients with food-induced allergic reactions in schools and other community settings have been developed; however, RCTs of the effectiveness of the interventions are needed to strengthen the evidence base for the recommendations [118].

\section{Long-term management: prevention of recurrence}

Regular follow-up of all patients at risk of anaphylaxis is an important principle of long-term risk reduction $[1,5,6]$. High-quality studies, including RCTs that focus on prevention of anaphylaxis are being published [119-150] (Table 4).

\section{Food-induced anaphylaxis}

A detailed history of the anaphylactic episode is a critically important aspect of patient evaluation. In interpreting the history, awareness of emerging new allergens and cross-reactivity of homologous allergenic proteins is helpful $[39,40,119]$.

Based on a retrospective study, for predicting outcomes of OFCs, the ratio of food-specific IgE to total

Table 4 Long-term management: trigger-specific prevention

Food-induced anaphylaxis [119-134]

Sustained clinical and immunological unresponsiveness to peanut was documented after up to 5 years of peanut oral immunotherapy. Responders had smaller skin test wheals and lower allergen-specific lgE levels at baseline and at the time of post-treatment peanut challenge, compared with non-responders [130].

Sustained clinical and immunological responsiveness to peanut has been documented after up to 3 years of peanut sublingual immunotherapy. Responders had a significant decrease in peanut-specific basophil activation and skin prick test titration with peanut, as compared with non-responders [131].

In selected high-risk infants with eczema, egg allergy, or both, who were aged 4-10 months (inclusive) at study entry, early introduction of peanut snacks (at least 6 grams weekly until age 60 months) prevented development of clinical reactivity to peanut [134].

Hymenoptera venom-induced anaphylaxis [135-139]

In 100 adults who completed venom immunotherapy and had live sting challenges to prove efficacy, post-challenge scores on the Vespid Allergy Quality of Life Questionnaire improved significantly, independent of age, sex, or severity of the initial anaphylaxis episode [138].

\section{Drug/iatrogenic agent-induced anaphylaxis [140-148]}

In a retrospective study of patients with a history of hypersensitivity reactions during anesthesia, comprehensive evaluation, including skin tests and measurement of basal tryptase levels, followed by development of a management plan, minimized risk of subsequent reactions even when a specific trigger such as an antibiotic, neuromuscular blocker, or latex was not identified [145].

Idiopathic anaphylaxis [149, 150]

In $20 \%$ of 110 patients with idiopathic anaphylaxis (no identifiable trigger by history, skin tests, or allergen-specific IgE levels), the etiology of the episode was identified by using the ImmunoCAP ISAC 103 allergen array in addition to the ImmunoCAP 250 platform. Omega-5 gliadin and shrimp were the most frequently identified sensitizations among those not previously recognized [149]. 
IgE was more accurate than specific IgE levels alone in confirming development of tolerance [120].

Component-resolved testing involves identifying specific IgE by using allergenic proteins derived from recombinant DNA technology or purified from natural sources. Among 165 consecutive peanut-sensitized children, those clinically reactive to peanut consistently had significantly higher peanut-specific and Ara $\mathrm{h}$ 2-specific IgE antibody levels than those who could tolerate peanut ingestion [121].

Use of the BAT in peanut-sensitized children revealed peanut concentration-dependent up-regulation of CD63 and CD203c in those who were clinically reactive to peanut, contrasting with no significant responses in those who could tolerate peanut ingestion. The BAT reduced the number of OFCs required [122].

The $65-70 \%$ of children destined to outgrow their anaphylactic sensitivity to milk or egg cannot be accurately identified by skin prick tests, nor can specific IgE levels be interpreted as an absolute indication or contraindication to an OFC. However, many caregivers can reliably report that their cow's milk- or egg-allergic child already eats and tolerates baked goods such as muffins containing small quantities of extensively-heated milk or egg without developing symptoms. For other children, such as a child who has been strictly avoiding cow's milk and related products, a physician-supervised cow's milk OFC is strongly recommended [119, 123-125].

Predictors of failure (clinical reactions, including anaphylaxis) during physician-supervised OFCs with baked cow's milk were: asthma, asthma requiring preventer therapy, IgE-mediated clinical reactions to more than three food groups, and a history of anaphylaxis to cow's milk [125].

A practical guide to managing cow's milk allergy and/ or egg allergy includes recipes for muffins containing baked milk or baked egg suitable for use in physiciansupervised OFCs in hospital settings and instructions for continuing safe introduction of baked milk or baked egg at home after a patient passes an OFC [124]. Useful web-based resources are also available [119].

Adherence, defined as regular dietary consumption of extensively heated cow's milk or egg, has been documented in two-thirds of children who passed a physician-supervised OFC. Children with asthma appear to be at increased risk of ongoing reactivity after passing an OFC [126].

Based on a validated disease-specific questionnaire, OFCs, regardless of pass or fail outcome, were associated with improved quality-of-life in caregivers of food-allergic children, as compared with caregivers of food-allergic children who did not have OFCs [127].

Liberalizing the diet is important for children who can tolerate baked milk or baked egg because strict elimination diets, particularly those excluding milk, have been associated with linear growth impairment and nutritional deficiencies, exclusion from social activities, and higher direct costs such as medications and indirect costs such as lost wages and household expenses [128, 129].

RCTs confirm that desensitization can be achieved in many patients who are symptomatic after ingestion of highly allergenic foods such as peanut, milk, or egg [130, 131]. During OIT, patients with asthma are at risk for more severe adverse events, including anaphylaxis [20], and are less likely to achieve full desensitization than nonasthmatics [132]. The safety of OIT can be improved by omalizumab pre-treatment and co-treatment [40].

Sustained clinical unresponsiveness to peanut after OIT has been demonstrated in a clinical trial in which children aged 1-16 years were treated with dose increases up to $4000 \mathrm{mg} /$ day peanut protein. Double-blind placebo-controlled OFCs with $5000 \mathrm{mg}$ peanut protein (on average, 12 peanuts) were conducted. Of 39 participants, 24 completed the protocol and 12 passed the OFC 1 month after stopping treatment. This study confirmed sustained unresponsiveness after up to 5 years of peanut OIT. Successful outcomes could be predicted by smaller skin test wheals to peanut and lower peanutspecific IgE levels at baseline and at the time of peanut challenge [130]. In an experimental OIT model, IgG antibodies that act through FcyRIIb to suppress IgEmediated hypersensitivity have been induced [133].

In a 3 year follow-up study of peanut sublingual immunotherapy, in OFCs performed 2 weeks after treatment ended, $11 \%$ of the 40 patients were able to consume 10 grams of peanut powder, equivalent to $16-18$ peanuts. Approximately $98 \%$ of the 18,165 doses were tolerated without severe symptoms beyond the oropharynx. At year 2 of maintenance treatment, responders had a significant decrease in peanut-specific basophil activation and SPT titration compared with non-responders. By study's end, $10.8 \%$ of 37 patients achieved sustained unresponsiveness to peanut. The drop-out rate was high, mainly due to difficulties in taking the sublingual peanut extract every day [131].

Prevention of clinical reactivity to peanut may eventually be possible. In a landmark RCT, 640 infants with severe eczema, egg allergy, or both, who were age 410 months at study entry were assigned to either consume peanuts or avoid peanuts until age 60 months. Randomization was based on pre-existing sensitization to peanut as determined by SPT. The primary outcome was the proportion of children with peanut allergy at age 60 months. In the infants who avoided peanut, the prevalence of peanut allergy was $13.7 \%$. In those who consumed at least 6 grams of a peanut butter-containing snack per week, it was significantly lower (1.9\%). In these carefully selected high-risk infants, early introduction of 
peanut prevented subsequent development of clinical reactivity to peanut [134]. Additional studies of prevention strategies are ongoing.

\section{Stinging insect-induced anaphylaxis}

Venom immunotherapy (VIT) effectively reduces susceptible patients' risk of recurrent SARs. The risk continues to decrease the longer VIT is continued. The currently recommended duration of VIT is 5 years; however, it should be given for more than 5 years to patients who are at particularly high risk for venom anaphylaxis, including the elderly, those with concomitant cardiac and/or pulmonary disease, elevated basal serum tryptase levels, and SARs before or during VIT. Lifelong VIT is the standard of care for patients with clonal mast cell disorders [135]. Omalizumab can be used to facilitate VIT in patients who previously could not tolerate it [136].

Because of the residual risk of SARs after VIT, all patients should carry EAIs indefinitely and continue to avoid Hymenoptera stings [135]. When teaching patients to avoid stinging insects and their nests, visual aids should be used to aid in recognition [137].

Sting challenge with a live insect is the only test that accurately evaluates VIT efficacy. In 100 adults who had completed VIT, after their sting challenges, scores on the Vespid Allergy Quality-of-Life Questionnaire improved significantly, independent of sex, age, and severity of the initial anaphylactic episode [138].

In some areas of Australia, jack jumper ant stings are an important cause of anaphylaxis and death. Jack jumper ant VIT effectively prevents anaphylaxis recurrences. Its tolerability and safety are comparable with those of honeybee VIT [139].

\section{Drug-induced/iatrogenic anaphylaxis}

In patients with a history of anaphylaxis to penicillins, if at all possible, skin tests, even SPT, and challenge tests should be avoided, because they can trigger anaphylaxis [140, 141].

In contrast, many (90\%) low-risk penicillin allergylabeled patients who have no history of anaphylaxis or other penicillin-associated serious life-threatening reactions can be de-labeled using a risk stratification protocol developed to guide skin testing and challenge tests. Compliance with recommendations for de-labeling can be increased by improved communication with patients and their physicians [142].

In 72 patients without HIV who had a history of sulfonamide adverse drug reactions, the outcomes of trimethoprim-sulfamethoxazole desensitization were evaluated for safety and efficacy after graded administration using short protocols (90 minutes to six hours), one-day protocols, or longer protocols. Desensitization was discontinued due to adverse reactions in only eight patients [143].

Paracetamol, a weak COX inhibitor, rarely triggers symptoms in patients with non-selective hypersensitivity reactions to NSAIDs. Use of a provocation test with paracetamol in children with a history of NSAID allergy is reported to exclude paracetamol as an inducer of anaphylaxis and identify it as a safe treatment option [144].

A retrospective study supports a comprehensive evaluation and management plan for patients with hypersensitivity reactions during anesthesia. Of 72 such patients referred to allergy/immunology, $18 \%$ had positive skin tests to beta-lactam antibiotics, neuromuscular blockers, latex, or other agents. One patient who had an elevated basal tryptase level was diagnosed with mastocytosis. On follow-up, $96 \%$ of the 47 patients requiring subsequent anesthesia tolerated it uneventfully. The two patients with recurrent reactions were later diagnosed with mast cell disorders [145].

IgA-deficient individuals with anti-IgA antibodies can develop anaphylaxis during transfusion of blood or blood products. As compared with time-consuming quantitative assays such as the fluorescein enzyme immunoassay, rapid non-quantitative DiaMed particle gel immunoassays for identifying IgA-deficiency and antibodies to IgA have reasonable sensitivity and specificity. They are potentially useful in emergency situations for diagnosing anti-IgA-related anaphylaxis and identifying donors who can provide IgA-deficient blood products [146].

Use of first-line chemotherapy and monoclonal agents for malignancies and chronic inflammatory diseases prolongs patient survival and minimizes morbidity. Desensitization should be considered when patients develop drug hypersensitivity to first-line agents and no alternative therapies are available, or when alternative treatments are considered to be therapeutically inferior and/or more toxic. The indications, protocols, and outcomes of desensitizations for chemotherapy and monoclonal antibodies in adults and children have been reviewed [147].

Influenza vaccine should not be withheld from eggsensitized patients, even those with a history of egginduced anaphylaxis [148]. The egg content of 2015 influenza vaccines is below the threshold needed to trigger reactions in egg-sensitized people. Injected and intranasal influenza vaccines have been studied in 4315 patients with egg allergy, including 656 patients with a history of anaphylaxis to ingested egg. The rare patients with a history of urticaria or anaphylaxis after immunization with influenza vaccine need an allergy/ immunology evaluation that includes skin tests to the vaccine itself [148]. 


\section{Idiopathic anaphylaxis}

In idiopathic anaphylaxis, by definition, meticulous history, skin tests and measurement of allergen-specific IgE levels have not revealed the trigger. In $20 \%$ of 110 patients with previously diagnosed idiopathic anaphylaxis, the etiology of the episode was identified by testing with the ImmunoCAP ISAC 103 allergen array in addition to the ImmunoCAP 250 platform. Omega-5 gliadin and shrimp accounted for $45 \%$ of the previously unrecognized sensitizations. Clinical reassessment substantiated the etiologic link in many patients [149].

In idiopathic anaphylaxis, there are no RCTs of interventions and no standardized treatment recommendations. Rituximab infusions induced remission of idiopathic anaphylaxis in a patient who had anaphylaxis symptoms every 3-30 days despite prophylaxis with high-dose $\mathrm{H}_{1}$ and $\mathrm{H}_{2}$-antihistamines, a leukotriene antagonist, systemic glucocorticoids, mycophenolate mofetil, omalizumab, and a diet restricted to three foods [150].

\section{Conclusions}

The recommendations for the assessment, management and prevention of anaphylaxis promulgated in the 2011 WAO Anaphylaxis Guidelines are supported and strengthened year-on-year by publication of new, relevant, epidemiological and experimental research findings, including some RCTs.

Important advances in 2014-2015 comprised further elucidation of patient risk factors and co-factors that amplify anaphylaxis, and greater insights into anaphylaxis triggers such as food, venom, and drugs, as well as idiopathic anaphylaxis. A prospective study documented the genomic basis of anaphylaxis and the cascade of mediators released during innate immune system activation in the first three hours after symptom onset.

High-quality observational studies published in 20142015 have confirmed that prompt injection of epinephrine reduces hospital admissions and that IM epinephrine injections are 10-fold safer than IV bolus injections. A study of anaphylaxis fatalities found that $23 \%$ of those who died did not receive epinephrine until cardiac arrest. New developments in long-term management of anaphylaxis include novel EAIs, prospective studies of anaphylaxis education, and substantial progress in use of immunomodulation to prevent anaphylactic episodes.

\footnotetext{
Abbreviations

ACE: Angiotensin-converting enzyme; Alpha-gal: Galactose-alpha 1,3-galactose; ASA: Acetylsalicylic acid; BAT: Basophil activation test; CVD: Cardiovascular disease; EAl: Epinephrine auto-injector; ECMO: Extracorporeal membrane oxygenation; ED: Emergency department; ICD: International Classification of Diseases; ICON: Anaphylaxis: International Consensus on Anaphylaxis; IM: Intramuscular; ISM: indolent systemic mastocytosis; IV: Intravenous; MCAS: Mast cell activation syndrome; NMBA: Neuromuscular blocking agent; NSAIDs: Non-steroidal anti-inflammatory drugs; OFC: Oral food challenge;
}

OIT: Oral immunotherapy; PAF: Platelet-activating factor; RCM: Radiocontrast media; RCT: Randomized controlled trial; SAR: Systemic allergic reaction; SPT: Skin prick tests; VIT: Venom immunotherapy; WAO: World Allergy Organization.

\section{Competing interests}

F. Estelle R. Simons: FERS is on the following Medical Advisory Boards: Allergopharma, Merck, Mylan, and Sanofi.

Motohiro Ebisawa: ME has no competing interests.

Mario Sanchez-Borges: Organizational: Member, Executive Committee, World Allergy Organization; Financial: Honorarium for educational purposes from Novartis Pharma AG.

Bernard Y. Thong: BYT has no competing interests.

Margitta Worm: MW is on the following Medical Advisory Boards: Mylan, Meda Pharma GmbH, ALK-Abello Arzneimittel GmbH, Allergopharma GmbH \& Co., KG.

Luciana Kase Tanno: LKT has no competing interests.

Richard F. Lockey: RFL has no competing interests.

Yehia El-Gamal: YEG has no competing interests.

Simon G.A. Brown: SGAB has no competing interests.

Hae-Sim Park: HSP has no competing interests.

Aziz Sheikh: AS has no competing interests.

\section{Authors' contributions}

FERS reviewed the anaphylaxis research published in peer-reviewed indexed journals from January 2014 through mid-year 2015, led the development of the 2015 Update, and prepared the initial, interim, and final drafts of the manuscript. ME was involved in the selection of studies for inclusion in this Update and commented critically on drafts of the manuscript. MSB was involved in the selection of studies for inclusion in this Update and commented critically on drafts of the manuscript. BYT was involved in the selection of studies for inclusion in this Update and commented critically on drafts of the manuscript. MW was involved in the selection of studies for inclusion in this Update and commented critically on drafts of the manuscript. LKT was involved in the selection of studies for inclusion in this Update and commented critically on drafts of the manuscript. RFL was involved in the selection of studies for inclusion in this manuscript and commented critically on drafts of the manuscript. YEG was involved in the selection of studies for inclusion in this manuscript. SGAB was involved in the selection of studies for inclusion in this manuscript. HSP was involved in the selection of studies for inclusion in this manuscript. AS was involved in the selection of studies for inclusion in this Update and commented critically on drafts of the manuscript. All authors are members of the WAO Anaphylaxis Committee, 2014-2015. All authors read and approved the final manuscript.

\section{Acknowledgments}

We acknowledge the support of WAO President, Dr. Lanny J. Rosenwasser, and the WAO Board of Directors. We also sincerely thank Lori McNiven, Health Sciences Centre, Winnipeg, MB, Canada for expert assistance.

\section{Author details}

'Department of Pediatrics \& Child Health and Department of Immunology, College of Medicine, Faculty of Health Sciences, The University of Manitoba, Room FE125, 820 Sherbrook Street, Winnipeg R3A 1R9 MB, Canada.

${ }^{2}$ Department of Allergy, Clinical Research Center for Allergy \& Rheumatology, Sagamihara National Hospital, Sagamihara, Kanagawa, Japan. ${ }^{3}$ Allergy and Clinical Immunology Department, Centro Medico-Docente La Trinidad, Caracas, Venezuela. ${ }^{4}$ Department of Rheumatology, Allergy \& Immunology, Tan Tock Seng Hospital, Singapore, Singapore. ${ }^{5}$ Allergie-Centrum-Charite, Klinik fur Dermatologie, Venerologie und Allergologie, Campus Charite Mitte, Universitatsmedizin, Berlin, Germany. ${ }^{6}$ Department of Allergy and Clinical Immunology, Hospital Servidor Publico Estadual de Sao Paulo and Hospital Sirio-Libanes, Sao Paulo, Brazil. ${ }^{7}$ University of South Florida College of Medicine, Tampa, FL, USA. ${ }^{8}$ Pediatric Allergy and Immunology Unit, Children's Hospital, Ain Shams University, Cairo, Egypt. ${ }^{9}$ Royal Hobart Hospital, Tasmania, and University of Western Australia and Royal Perth Hospital, Perth, Western Australia. ${ }^{10}$ Department of Allergy \& Clinical Immunology, Ajou University School of Medicine, Seoul, South Korea. ${ }^{11}$ Allergy \& Respiratory Research Group, Usher Institute of Population Health Sciences and Informatics, The University of Edinburgh, Edinburgh, UK. 
Received: 6 August 2015 Accepted: 25 September 2015 Published: 28 October 2015

\section{References}

1. Simons FER, Ardusso LRF, Bilo MB, El-Gamal YM, Ledford DK, Ring J, et al. for the World Allergy Organization. World Allergy Organization guidelines for the assessment and management of anaphylaxis. J Allergy Clin Immunol. 2011;127:587-93. e1-e22.

2. Simons FER, Ardusso LRF, Bilo MB, Dimov V, Ebisawa M, El-Gamal YM, et al. for the World Allergy Organization. 2012 Update: World Allergy Organization (WAO) guidelines for the assessment and management of anaphylaxis. Curr Opin Allergy Clin Immunol. 2012;12:389-99.

3. Simons FER, Ardusso LRF, Dimov V, Ebisawa M, El-Gamal YM, Lockey RF, et al. for the World Allergy Organization. World Allergy Organization anaphylaxis guidelines: 2013 update of the evidence base. Int Arch Allergy Immunol. 2013;162:193-204.

4. Simons FER, Ardusso LRF, Bilo MB, Cardona V, Ebisawa M, El-Gamal YM, et al. International consensus on (ICON) anaphylaxis. WAO J. 2014;7:9.

5. Muraro A, Roberts G, Worm M, Bilò MB, Brockow K, Fernández Rivas M, et al. Anaphylaxis: guidelines from the European Academy of Allergy and Clinical Immunology. Allergy. 2014;69:1026-45.

6. Lieberman P, Nicklas RA, Randolph C, Oppenheimer J, Bernstein D, Bernstein J, et al. Anaphylaxis - a practice parameter update 2015. Ann Allergy Asthma Immunol. (in press).

7. Tejedor Alonso MA, Moro Moro M, Múgica García MV. Epidemiology of anaphylaxis. Clin Exp Allergy. 2015;45:1027-39.

8. Wood RA, Camargo Jr CA, Lieberman P, Sampson HA, Schwartz LB, Zitt M, et al. Anaphylaxis in America: The prevalence and characteristics of anaphylaxis in the United States. J Allergy Clin Immunol. 2014;133:461-7.

9. Rudders SA, Arias SA, Camargo Jr CA. Trends in hospitalizations for foodinduced anaphylaxis in US children, 2000-2009. J Allergy Clin Immunol. 2014;134:960-2. e3.

10. Nocerino R, Leone L, Cosenza L, Canani RB. Increasing rate of hospitalizations for food-induced anaphylaxis in Italian children: an analysis of the Italian Ministry of Health database. J Allergy Clin Immunol. 2015;135:833-35. e3.

11. Mullins RJ, Dear KBG, Tang MLK. Time trends in Australian hospital anaphylaxis admissions in 1998-1999 to 2011-2012. J Allergy Clin Immunol. 2015;136:367-75.

12. Turner PJ, Gowland MH, Sharma V, lerodiakonou D, Harper N, Garcez T, et al. Increase in anaphylaxis-related hospitalizations but no increase in fatalities: An analysis of United Kingdom national anaphylaxis data, 1992-2012. J Allergy Clin Immunol. 2015;135:956-63. e1.

13. Ma L, Danoff TM, Borish L. Case fatality and population mortality associated with anaphylaxis in the United States. J Allergy Clin Immunol. 2014;133:1075-83.

14. Jerschow E, Lin RY, Scaperotti MM, McGinn AP. Fatal anaphylaxis in the United States, 1999-2010: Temporal patterns and demographic associations. J Allergy Clin Immunol. 2014;134:1318-28. e7.

15. Tanno LK, Calderon MA, Goldberg BJ, Akdis CA, Papadopoulos NG, Demoly P. Categorization of allergic disorders in the new World Health Organization International Classification of Diseases. Clin Transl Allergy. 2014:4:42

16. Tanno LK, Calderon MA, Goldberg BJ, Gayraud J, Bircher AJ, Casale T, et al. Constructing a classification of hypersensitivity/allergic diseases for ICD-11 by crowdsourcing the allergist community. Allergy. 2015;70:609-15.

17. Clark S, Wei W, Rudders SA, Camargo Jr CA. Risk factors for severe anaphylaxis in patients receiving anaphylaxis treatment in US emergency departments and hospitals. J Allergy Clin Immunol. 2014;134:1125-30.

18. Ye YM, Kim MK, Kang HR, Kim TB, Sohn SW, Koh Yl, et al. for the KAAAC Work Group on Urticaria/Angioedema/Anaphylaxis. Predictors of the severity and serious outcomes of anaphylaxis in Korean adults: a multicenter retrospective case study. Allergy Asthma Immunol Res. 2015;7:22-9.

19. Simons FER, Sampson HA. Anaphylaxis: Unique aspects of clinical diagnosis and management in infants (birth to age 2 years). J Allergy Clin Immunol. 2015;135:1125-31.

20. Vazquez-Ortiz M, Alvaro M, Piquer M, Giner MT, Dominguez O, Lozano J, et al. Life-threatening anaphylaxis to egg and milk oral immunotherapy in asthmatic teenagers. Ann Allergy Asthma Immunol. 2014;113:482-4.

21. Rutkowski K, Nasser SM. Management of hypersensitivity reactions to anti-D immunoglobulin preparations. Allergy. 2014;69:1560-3.
22. Triggiani M, Montagni M, Parente R, Ridolo E. Anaphylaxis and cardiovascular diseases: a dangerous liaison. Curr Opin Allergy Clin Immunol. 2014;14:309-15.

23. Lieberman P, Simons FER. Anaphylaxis and cardiovascular disease: therapeutic dilemmas. Clin Exp Allergy. 2015;45:1288-95.

24. Rueff F, Vos B, Oude Elberink J, Bender A, Chatelain R, Dugas-Breit S, et al. Predictors of clinical effectiveness of Hymenoptera venom immunotherapy. Clin Exp Allergy. 2014:44:736-46.

25. Stoevesandt J, Hain J, Stolze I, Kerstan A, Trautmann A. Angiotensinconverting enzyme inhibitors do not impair the safety of Hymenoptera venom immunotherapy build-up phase. Clin Exp Allergy. 2014;44:747-55.

26. Nassiri M, Babina M, Dölle S, Edenharter G, Ruëff F, Worm M. Ramipril and metoprolol intake aggravate human and murine anaphylaxis: Evidence for direct mast cell priming. J Allergy Clin Immunol. 2015;135:491-9.

27. Valent $P$. Risk factors and management of severe life-threatening anaphylaxis in patients with clonal mast cell disorders. Clin Exp Allergy. 2014;44:914-20.

28. Gulen T, Hagglund H, Sander B, Dahlen B, Nilsson G. The presence of mast cell clonality in patients with unexplained anaphylaxis. Clin Exp Allergy. 2014:44:1179-87.

29. Alvarez-Twose I, Zanotti R, Gonzalez-de-Olano D, Bonadonna P, Vega A, Matito A, et al. Nonaggressive systemic mastocytosis (SM) without skin lesions associated with insect-induced anaphylaxis shows unique features versus other indolent SM. J Allergy Clin Immunol. 2014;133:520-8.

30. Broesby-Olsen S, Oropeza AR, Bindslev-Jensen C, Vestergaard H, Møller $M B$, Siebenhaar $F$, et al. Recognizing mastocytosis in patients with anaphylaxis: Value of KIT D816V mutation analysis of peripheral blood. J Allergy Clin Immunol. 2015;135:262-4.

31. Fellinger C, Hemmer W, Wohrl S, Sesztak-Greinecker G, Jarisch R, Wantke F. Clinical characteristics and risk profile of patients with elevated baseline serum tryptase. Allergol Immunopathol (Madr). 2014;42:544-52.

32. Pravettoni V, Piantanida M, Primavesi L, Forti S, Pastorello EA. Basal platelet-activating factor acetylhydrolase: Prognostic marker of severe Hymenoptera venom anaphylaxis. J Allergy Clin Immunol. 2014;133:1218-20

33. Lyons JJ, Sun G, Stone KD, Nelson C, Wisch L, O'Brien M, et al. Mendelian inheritance of elevated serum tryptase associated with atopy and connective tissue abnormalities. J Allergy Clin Immunol. 2014;133:1471-4.

34. Fischer J, Hebsaker J, Caponetto P, Platts-Mills TA, Biedermann T. Galactosealpha-1,3-galactose sensitization is a prerequisite for pork-kidney allergy and cofactor-related mammalian meat anaphylaxis. J Allergy Clin Immunol. 2014;134:755-9. e1.

35. Ansley L, Bonini M, Delgado L, Del Giacco S, Du Toit G, Khaitov M, et al. Pathophysiological mechanisms of exercise-induced anaphylaxis: an EAACl position statement. Allergy. 2015;70:1212-21.

36. Brockow K, Kneissl D, Valentini L, Zelger O, Grosber M, Kugler C, et al. Using a gluten oral food challenge protocol to improve diagnosis of wheat-dependent exercise-induced anaphylaxis. J Allergy Clin Immunol. 2015;135:977-84. e4.

37. Hox V, Desai A, Bandara G, Gilfillan AM, Metcalfe DD, Olivera A. Estrogen increases the severity of anaphylaxis in female mice through enhanced endothelial nitric oxide synthase expression and nitric oxide production. J Allergy Clin Immunol. 2015;135:729-36. e5.

38. Worm M, Moneret-Vautrin A, Scherer K, Lang R, Fernandez-Rivas M, Cardona $V$, et al. First European data from the network of severe allergic reactions (NORA). Allergy. 2014;69:1397-404.

39. Sicherer SH, Sampson HA. Food allergy: epidemiology, pathogenesis, diagnosis, and treatment. J Allergy Clin Immunol. 2014;133:291-307.

40. Sampson HA, Aceves S, Bock SA, James J, Jones S, Lang D, et al. Food allergy: a practice parameter update - 2014. J Allergy Clin Immunol. 2014;134:1016-25. e43

41. Umasunthar T, Leonardi-Bee J, Turner PJ, Hodes M, Gore C, Warner JO, et al. Incidence of food anaphylaxis in people with food allergy: a systematic review and meta-analysis. Clin Exp Allergy. 2015;45:1621-1636.

42. Kamdar TA, Peterson S, Lau CH, Saltoun CA, Gupta RS, Bryce PJ. Prevalence and characteristics of adult-onset food allergy. J Allergy Clin Immunol Pract. 2015;3:114-5. e1.

43. Vetander M, Ly DH, Hakansson N, Lilja G, Nilsson C, Ostblom E, et al. Recurrent reactions to food among children at paediatric emergency 
departments: epidemiology of allergic disease. Clin Exp Allergy. 2014;44:113-20.

44. van der Valk JPM, Dubois AEJ, Gerth van Wijk R, Wichers HJ, de Jong NW. Systematic review on cashew nut allergy. Allergy. 2014;69:692-8.

45. Commins SP, James HR, Stevens W, Pochan SL, Land MH, King C, et al. Delayed clinical and ex vivo response to mammalian meat in patients with lgE to galactose-alpha-1,3-galactose. J Allergy Clin Immunol. 2014;134:108-15.

46. Takahashi K, Taniguchi M, Fukutomi Y, Sekiya K, Watai K, Mitsui C, et al. Ora mite anaphylaxis caused by mite-contaminated okonomiyaki/pancake-mix in Japan: 8 case reports and a review of 28 reported cases. Allergol Int. 2014;63:51-6.

47. Kelso JM. Potential food allergens in medications. J Allergy Clin Immunol. 2014;133:1509-18

48. Levy Y, Segal N, Nahum A, Marcus N, Garty BZ. Hypersensitivity to methylprednisolone sodium succinate in children with milk allergy. J Allergy Clin Immunol Pract. 2014;2:471-4.

49. Hamilton RG, Scheer DI, Gruchalla R, Adkinson NF, Sampson HA. Casein-related anaphylaxis after use of an Everlast kickboxing glove. J Allergy Clin Immunol. 2015;135:269-71

50. Golden DB. New directions in diagnostic evaluation of insect allergy. Curr Opin Allergy Clin Immunol. 2014;14:334-9.

51. Casale TB, Burks AW. Hymenoptera-sting hypersensitivity. N Engl J Med. 2014;370:1432-9.

52. Sturm GJ, Kranzelbinder B, Schuster C, Sturm EM, Bokanovic D, Vollmann J, et al. Sensitization to Hymenoptera venoms is common, but systemic sting reactions are rare. J Allergy Clin Immunol. 2014;133:1635-43. e1.

53. Cifuentes L, Vosseler S, Blank S, Seismann H, Darsow U, Bredehorst R, et al. Identification of Hymenoptera venom-allergic patients with negative specific IgE to venom extract by using recombinant allergens. J Allergy Clin Immunol. 2014;133:909-10.

54. Kohler J, Blank S, Muller S, Bantleon F, Frick M, Huss-Marp J, et al. Component resolution reveals additional major allergens in patients with honeybee venom allergy. J Allergy Clin Immunol. 2014;133:1383-9. e6.

55. Banerji A, Rudders S, Clark S, Wei W, Long AA, Camargo Jr CA. Retrospective study of drug-induced anaphylaxis treated in the emergency department or hospital: patient characteristics, management, and 1-year follow-up. J Allergy Clin Immunol Pract. 2014;2:46-51.

56. Jares EJ, Sánchez-Borges M, Cardona-Villa R, Ensina LF, Arias-Cruz A, Gómez $M$, et al. Multinational experience with hypersensitivity drug reactions in Latin America. Ann Allergy Asthma Immunol. 2014;113:282-9.

57. Demoly P, Adkinson NF, Brockow K, Castells M, Chiriac AM, Greenberger PA, et al. International consensus on drug allergy. Allergy. 2014;69:420-37.

58. Macy E, Contreras R. Health care use and serious infection prevalence associated with penicillin "allergy" in hospitalized patients: A cohort study. J Allergy Clin Immunol. 2014;133:790-6.

59. Li M, Krishna MT, Razaq S, Pillay D. A real-time prospective evaluation of clinical pharmaco-economic impact of diagnostic label of "penicillin allergy" in a UK teaching hospital. J Clin Pathol. 2014;67:1088-92.

60. Fox SJ, Park MA. Penicillin skin testing is a safe and effective tool for evaluating penicillin allergy in the pediatric population. J Allergy Clin Immunol Pract. 2014;2:439-44.

61. Macy E, Contreras R. Adverse reactions associated with oral and parenteral use of cephalosporins: A retrospective population-based analysis. J Allergy Clin Immunol. 2015;135:745-52.

62. Gaeta F, Valluzzi RL, Alonzi C, Maggioletti M, Caruso C, Romano A. Tolerability of aztreonam and carbapenems in patients with IgE-mediated hypersensitivity to penicillins. J Allergy Clin Immunol. 2015;135:972-6.

63. Uyttebroek AP, Sabato V, Bridts CH, De Clerck LS, Ebo DG. Moxifloxacin hypersensitivity: uselessness of skin testing. J Allergy Clin Immunol Pract. 2015;3:443-5.

64. Mori F, Pecorari L, Pantano S, Rossi ME, Pucci N, De Martino M, et al. Azithromycin anaphylaxis in children. Int J Immunopathol Pharmacol. 2014;27:121-6.

65. Aun MV, Blanca M, Garro LS, Ribeiro MR, Kalil J, Motta AA, et al. Nonsteroidal anti-inflammatory drugs are major causes of drug-induced anaphylaxis. J Allergy Clin Immunol Pract. 2014;2:414-20.

66. Faria E, Rodrigues-Cernadas J, Gaspar A, Botelho C, Castro E, Lopes A, et al. Drug-induced anaphylaxis survey in Portuguese allergy departments. J Investig Allergol Clin Immunol. 2014;24:40-8.

67. Picaud J, Beaudouin E, Renaudin JM, Pirson F, Metz-Favre C, Dron-Gonzalvez $\mathrm{M}$, et al. Anaphylaxis to diclofenac: nine cases reported to the Allergy Vigilance Network in France. Allergy. 2014;69:1420-3.
68. Craig TJ, Li H, Riedl M, Bernstein JA, Lumry WR, MacGinnitie AJ, et al. Characterization of anaphylaxis after ecallantide treatment of hereditary angioedema attacks. J Allergy Clin Immunol Pract. 2015;3:206-12.

69. Galvao VR, Castells MC. Hypersensitivity to biological agents - updated diagnosis, management, and treatment. J Allergy Clin Immunol Pract. 2015;3:175-85.

70. Savic LC, Kaura V, Yusaf M, Hammond-Jones AM, Jackson R, Howell S, et al. Incidence of suspected perioperative anaphylaxis: A multicenter snapshot study. J Allergy Clin ImmunolPract. 2015;3:454-5. e1.

71. Reitter M, Petitpain N, Latarche C, Cottin J, Massy N, Demoly P, et al. Fatal anaphylaxis with neuromuscular blocking agents: a risk factor and management analysis. Allergy. 2014;69:954-9.

72. Tsur A, Kalansky A. Hypersensitivity associated with sugammadex administration: a systematic review. Anaesthesia. 2014;69:1251-7.

73. Opstrup MS, Malling HJ, Kroigaard M, Mosbech H, Skov PS, Poulsen LK, et al. Standardized testing with chlorhexidine in perioperative allergy - a large single-centre evaluation. Allergy. 2014;69:1390-6.

74. Péer L, Brezis ML, Shalit M, Carvalho B, Levin PD, Seri O, et al. Evaluation of a prospectively administered written questionnaire to reduce the incidence of suspected latex anaphylaxis during elective cesarean delivery. Int J Obstet Anesth. 2014;23:335-40.

75. Kim MH, Lee SY, Lee SE, Yang MS, Jung JW, Park CM, et al. Anaphylaxis to iodinated contrast media: clinical characteristics related with development of anaphylactic shock. PLoS One. 2014;9:e100154.

76. Raisch DW, Garg V, Arabyat R, Shen X, Edwards BJ, Miller FH, et al. Anaphylaxis associated with gadolinium-based contrast agents: data from the Food and Drug Administration's adverse event reporting system and review of case reports in the literature. Expert Opin Drug Saf. 2014;13:15-23.

77. Ha SO, Kim DY, Sohn CH, Lim KS. Anaphylaxis caused by intravenous fluorescein: clinical characteristics and review of literature. Intern Emerg Med. 2014:9:325-30

78. Campbell RL, Li JT, Nicklas RA, Sadosty AT. Emergency department diagnosis and treatment of anaphylaxis: a practice parameter. Ann Allergy Asthma Immunol. 2014;113:599-608.

79. Wang J, Young MC, Nowak-Węgrzyn A. International survey of knowledge of food-induced anaphylaxis. Pediatr Allergy Immunol. 2014;25:644-50.

80. Sargant N, Erlewyn-Lajeunesse M, Benger J. Does anaphylaxis masquerade as asthma in children? Emerg Med J. 2015;32:83-4.

81. Murali MR, Uyeda JW, Tingpej B. Case 2-2015: a 25-year-old man with abdominal pain, syncope, and hypotension. N Engl J Med. 2015;372:265-73.

82. Hsu P, Xie Z, Frith K, Wong M, Kakakios A, Stone KD, et al. Idiopathic systemic capillary leak syndrome in children. Pediatrics. 2015;135:e730-5.

83. Sherenian MG, Clee M, Schondelmeyer AC, de Alarcon A, Li J, Assa'ad A, et al. Caustic ingestions mimicking anaphylaxis: case studies and literature review. Pediatrics. 2015;135:e547-50.

84. Plumb B, Bright P, Gompels MM, Unsworth DJ. Correct recognition and management of anaphylaxis: not much change over a decade. Postgrad Med J. 2015;91:3-7.

85. Wongkaewpothong P, Pacharn P, Sripramong C, Boonchoo S, Piboonpocanun $\mathrm{S}$, Visitsunthorn $\mathrm{N}$, et al. The utility of serum tryptase in the diagnosis of food-induced anaphylaxis. Allergy Asthma Immunol Res. 2014;6:304-9

86. Laroche D, Gomis P, Gallimidi E, Malinovsky JM, Mertes PM. Diagnostic value of histamine and tryptase concentrations in severe anaphylaxis with shock or cardiac arrest during anesthesia. Anesthesiology. 2014;121:272-9.

87. Krishna MT, York M, Chin T, Gnanakumaran G, Heslegrave J, Derbridge C, et al. Multi-centre retrospective analysis of anaphylaxis during general anaesthesia in the United Kingdom: aetiology and diagnostic performance of acute serum tryptase. Clin Exp Immunol. 2014;178:399-404.

88. McLean-Tooke A, Goulding M, Bundell C, White J, Hollingsworth P. Postmortem serum tryptase levels in anaphylactic and non-anaphylactic deaths. J Clin Pathol. 2014;67:134-8.

89. Sala-Cunill A, Bjorkqvist J, Senter R, Guilarte M, Cardona V, Labrador M, et al. Plasma contact system activation drives anaphylaxis in severe mast cellmediated allergic reactions. J Allergy Clin Immunol. 2015;135:1031-43. e6.

90. Stone SF, Bosco A, Jones A, Cotterell CL, van Eeden PE, Arendts G, et al. Genomic responses during acute human anaphylaxis are characterized by upregulation of innate inflammatory gene networks. PLoS One. 2014;9:e101409.

91. Dhami S, Panesar SS, Roberts G, Muraro A, Worm M, Bilò MB, et al. Management of anaphylaxis: a systematic review. Allergy. 2014;69:168-75. 
92. Fleming JT, Clark S, Camargo CA, Rudders SA. Early treatment of foodinduced anaphylaxis with epinephrine is associated with a lower risk of hospitalization. J Allergy Clin Immunol Pract. 2015;3:57-62.

93. Xu YS, Kastner M, Harada L, Xu A, Salter J, Waserman S. Anaphylaxis-related deaths in Ontario: a retrospective review of cases from 1986 to 2011. Allergy Asthma Clin Immunol. 2014;10:38.

94. Hitti EA, Zaitoun F, Harmouche E, Saliba M, Mufarrij A. Acute allergic reactions in the emergency department: characteristics and management practices. Eur J Emerg Med. 2015;22:253-9.

95. Manivannan V, Hess EP, Bellamkonda VR, Nestler DM, Bellolio MF, Hagan JB, et al. A multifaceted intervention for patients with anaphylaxis increases epinephrine use in adult emergency department. J Allergy Clin Immunol Pract. 2014;2:294-9. e1.

96. Asai Y, Yanishevsky Y, Clarke A, La Vieille S, Delaney JS, Alizadehfar R, et al. Rate, triggers, severity and management of anaphylaxis in adults treated in a Canadian emergency department. Int Arch Allergy Immunol. 2014;164:246-52.

97. Chung T, Gaudet L, Vandenberghe C, Couperthwaite S, Sookram S, Liss K, et al. Pre-hospital management of anaphylaxis in one Canadian urban centre. Resuscitation. 2014;85:1077-82.

98. Manivannan V, Hyde RJ, Hankins DG, Bellolio MF, Fedko MG, Decker WW et al. Epinephrine use and outcomes in anaphylaxis patients transported by emergency medical services. Am J Emerg Med. 2014;32:1097-102.

99. Campbell RL, Bellolio MF, Knutson BD, Bellamkonda VR, Fedko MG, Nestler DM, et al. Epinephrine in anaphylaxis: higher risk of cardiovascular complications and overdose after administration of intravenous bolus epinephrine compared with intramuscular epinephrine. J Allergy Clin Immunol Pract. 2015;3:76-80.

100. Nurmatov UB, Rhatigan $E_{1}$ Simons FER, Sheikh $A$. $\mathrm{H}_{2}$-antihistamines for the treatment of anaphylaxis with and without shock: a systematic review. Ann Allergy Asthma Immunol. 2014;112:126-31.

101. Lee S, Bellolio MF, Hess EP, Erwin P, Murad MH, Campbell RL. Time of onset and predictors of biphasic anaphylactic reactions: a systematic review and meta-analysis. J Allergy Clin Immunol Pract. 2015;3:408-16.

102. Lo JCY, Darracq MA, Clark RF. A review of methylene blue treatment for cardiovascular collapse. J Emerg Med. 2014:46:670-9.

103. Zhang Z, Su X, Liu C. Cardiac arrest with anaphylactic shock: a successful resuscitation using extracorporeal membrane oxygenation. Am J Emerg Med. 2015;33:130.e3-4.

104. Campbell RL, Park MA, Kueber MA, Lee S, Hagan JB. Outcomes of allergy/ immunology follow-up after an emergency department evaluation for anaphylaxis. J Allergy Clin Immunol Pract. 2015;3:88-93.

105. Altman AM, Camargo CA, Simons FER, Lieberman P, Sampson HA, Schwartz LB, et al. Anaphylaxis in America: a national physician survey. J Allergy Clin Immunol. 2015;135:830-3.

106. Bonds RS, Asawa A, Ghazi Al. Misuse of medical devices: a persistent problem in self-management of asthma and allergic disease. Ann Allergy Asthma Immunol. 2015;114:74-6.

107. Edwards ES, Edwards ET, Simons FER, North R. Drug-device combination products in the $21^{\text {st }}$ century: development using a human factors engineering approach. Expert Opin Drug Deliv. 2015;12:751-62.

108. Umasunthar T, Procktor A, Hodes M, Smith JG, Gore C, Cox HE, et al. Patients' ability to treat anaphylaxis using adrenaline auto-injectors: a randomized controlled trial. Allergy. 2015;70:855-63.

109. Rachid O, Simons FER, Wein MB, Rawas-Qalaji M, Simons KJ. Epinephrine doses contained in outdated epinephrine auto-injectors collected in a Florida allergy practice. Ann Allergy Asthma Immunol. 2015;114:354-6. e1.

110. Rachid O, Simons FER, Rawas-Qalaji M, Lewis S, Simons KJ. Epinephrine autoinjectors: does freezing or refrigeration affect epinephrine dose delivery and enantiomeric purity? J Allergy Clin Immunol Pract. 2015;3:294-6.

111. Topal E, Bakirtas A, Yilmaz O, Karagol IHE, Arga M, Demirsoy MS, et al. When should we perform a repeat training on adrenaline auto-injector use for physician trainees? Allergol Immunopathol (Madr). 2014;42:472-5.

112. Brockow K, Schallmayer S, Beyer K, Biedermann T, Fischer J, Gebert N, et al. including the working group on anaphylaxis training education (AGATE). Effects of a structured educational intervention on knowledge and emergency management in patients at risk for anaphylaxis. Allergy. 2015;70:227-35

113. Salter SM, Vale S, Sanfilippo FM, Loh R, Clifford RM. Long-term effectiveness of online anaphylaxis education for pharmacists. Am J Pharm Educ. 2014;78:136
114. Zadikoff EH, Whyte SA, DeSantiago-Cardenas L, Harvey-Gintoft B, Gupta RS The development and implementation of the Chicago public schools emergency EpiPen policy. J Sch Health. 2014;84:342-7.

115. Mok G, Vaillancourt R, Irwin D, Wong A, Zemek R, Alqurashi W. Design and validation of pictograms in a pediatric anaphylaxis action plan. Pediatr Allergy Immunol. 2015;26:223-33.

116. Wahl A, Stephens H, Ruffo M, Jones AL. The evaluation of a food allergy and epinephrine autoinjector training program for personnel who care for children in schools and community settings. J Sch Nurs. 2015;31:91-8.

117. Le TM, Kummeling I, Dixon D, Tolosa LB, Ballmer-Weber B, Clausen M, et al. Low preparedness for food allergy as perceived by school staff: a EuroPrevall survey across Europe. J Allergy Clin Immunol Pract. 2014;2:480-2. e1.

118. Muraro A, Agache I, Clark A, Sheikh A, Roberts G, Akdis CA, et al. EAACl Food Allergy and Anaphylaxis Guidelines: managing patients with food allergy in the community. Allergy. 2014;69:1046-57.

119. Bird JA, Lack G, Perry TT. Clinical management of food allergy. J Allergy Clin Immunol Pract. 2015:3:1-11.

120. Gupta RS, Lau CH, Hamilton RG, Donnell A, Newhall KK. Predicting outcomes of oral food challenges by using the allergen-specific lgE-total IgE ratio. J Allergy Clin Immunol Pract. 2014;2:300-5.

121. Ebisawa M, Moverare R, Sato S, Borres MP, Ito K. The predictive relationship between peanut- and Ara h2-specific serum IgE concentrations and peanut allergy. J Allergy Clin Immunol Pract. 2015;3:131-2. e1.

122. Santos AF, Douiri A, Bécares N, Wu SY, Stephens A, Radulovic S, et al. Basophil activation test discriminates between allergy and tolerance in peanut-sensitized children. J Allergy Clin Immunol. 2014;134:645-52.

123. Turner PJ, Kumar K, Fox AT. Skin testing with raw egg does not predict tolerance to baked egg in egg-allergic children. Pediatr Allergy Immunol. 2015:25:657-61.

124. Leonard SA, Caubet JC, Kim JS, Groetch M, Nowak-Wegrzyn A. Baked milk- and egg-containing diet in the management of milk and egg allergy. J Allergy Clin Immunol Pract. 2015;3:13-23.

125. Mehr S, Turner PJ, Joshi P, Wong M, Campbell DE. Safety and clinical predictors of reacting to extensively heated cow's milk challenge in cow's milk-allergic children. Ann Allergy Asthma Immunol. 2014;113:425-9.

126. Lee E, Mehr S, Turner PJ, Joshi P, Campbell DE. Adherence to extensively heated egg and cow's milk after successful oral food challenge. J Allergy Clin Immunol Pract. 2015;3:125-7. e4.

127. Franxman TJ, Howe L, Teich E, Greenhawt MJ. Oral food challenge and food allergy quality of life in caregivers of children with food allergy. J Allergy Clin Immunol Pract. 2015;3:50-6.

128. Mehta H, Ramesh M, Feuille E, Groetch M, Wang J. Growth comparison in children with and without food allergies in 2 different demographic populations. J Pediatr. 2014;165:842-8.

129. Protudjer JLP, Jansson SA, Arnlind MH, Bengtsson U, Kallstrom-Bengtsson I, Marklund B, et al. Household costs associated with objectively diagnosed allergy to staple foods in children and adolescents. J Allergy Clin Immunol Pract. 2015;3:68-75.

130. Vickery BP, Scurlock AM, Kulis M, Steele PH, Kamilaris J, Berglund JP, et al. Sustained unresponsiveness to peanut in subjects who have completed peanut oral immunotherapy. J Allergy Clin Immunol. 2014;133:468-75. e6.

131. Burks AW, Wood RA, Jones SM, Sicherer SH, Fleischer DM, Scurlock AM, et al. Sublingual immunotherapy for peanut allergy: long-term follow-up of a randomized multicenter trial. J Allergy Clin Immunol. 2015;135:1240-8.

132. Elizur A, Goldberg MR, Levy MB, Nachshon L, Katz Y. Oral immunotherapy in cow's milk allergic patients: course and long-term outcome according to asthma status. Ann Allergy Asthma Immunol. 2015;114:240-4.

133. Burton OT, Logsdon SL, Zhou JS, Medina-Tamayo J, Abdel-Gadir A, Rivas $M N$, et al. Oral immunotherapy induces lgG antibodies that act through FcyRIlb to suppress IgE-mediated hypersensitivity. J Allergy Clin Immunol. 2014;134:1310-7.

134. Du Toit G, Roberts G, Sayre PH, Bahnson HT, Radulovic S, Santos AF, et al. Randomized trial of peanut consumption in infants at risk for peanut allergy. N Engl J Med. 2015;372:803-13.

135. Muller UR, Ring J. When can immunotherapy for insect sting allergy be stopped? J Allergy Clin Immunol Pract. 2015;3:324-8.

136. Palgan K, Bartuzi Z, Gotz-Zbikowska M. Treatment with a combination of omalizumab and specific immunotherapy for severe anaphylaxis after a wasp sting. Int J Immunopathol Pharmacol. 2014;27:109-12. 
137. Baker TW, Forester JP, Johnson ML, Stolfi A, Stahl MC. The HIT study: Hymenoptera Identification Test - how accurate are people at identifying stinging insects? Ann Allergy Asthma Immunol. 2014;113:267-70.

138. Koschel DS, Schmies M, Weber CN, Hoffken G, Balck F. Tolerated sting challenge in patients on Hymenoptera venom immunotherapy improves health-related quality of life. J Investig Allergol Clin Immunol. 2014;24:226-30.

139. Mullins RJ, Brown SGA. Ant venom immunotherapy in Australia: the unmet need. Med J Aust. 2014;201:33-4.

140. Syrigou E, Syrigos K. Anaphylaxis during skin prick testing for amoxicillin allergy. J Allergy Clin Immunol Pract. 2014;2:478-9.

141. Park MA, Solensky R, Khan DA, Castells MC, Macy EM, Lang DM. Patients with positive skin test results to penicillin should not undergo penicillin or amoxicillin challenge. J Allergy Clin Immunol. 2015;135:816-7.

142. Bourke J, Pavlos R, James I, Phillips E. Improving the effectiveness of penicillin allergy de-labeling. J Allergy Clin Immunol Pract. 2015;3:365-74.

143. Pyle RC, Butterfield JH, Volcheck GW, Podjasek JC, Rank MA, Li JTC, et al. Successful outpatient graded administration of trimethoprimsulfamethoxazole in patients without HIV and with a history of sulfonamide adverse drug reaction. J Allergy Clin Immunol Pract. 2014;2:52-8.

144. Ensina LF, de Lacerda AE, de Andrade DM, Machado L, Camelo-Nunes I, Solé D. Drug-induced anaphylaxis in children: Nonsteroidal anti-inflammatory drugs and drug provocation test. J Allergy Clin Immunol Pract. 2014;2:825.

145. Guyer AC, Saff RR, Conroy M, Blumenthal KG, Camargo CA, Long AA, et al. Comprehensive allergy evaluation is useful in the subsequent care of patients with drug hypersensitivity reactions during anesthesia. J Allergy Clin Immunol Pract. 2015;3:94-100.

146. Oltean S, Epure A, Lindstrom K, Pardi C. Detection of anti-lgA antibodies using the particle gel immunoassay: a rapid test for increased patient safety. Blood Transfus. 2014;12:334-9.

147. Hong DI, Dioun AF. Indications, protocols, and outcomes of drug desensitizations for chemotherapy and monoclonal antibodies in adults and children. J Allergy Clin Immunol Pract. 2014;2:13-9.

148. Kelso JM. Influenza vaccine and egg allergy: nearing the end of an evidence-based journey. J Allergy Clin Immunol Pract. 2015;3:140-1.

149. Heaps A, Carter S, Selwood C, Moody M, Unsworth J, Deacock S, et al. The utility of the ISAC allergen array in the investigation of idiopathic anaphylaxis. Clin Exp Immunol. 2014;177:483-90.

150. Borzutzky A, Morales PS, Mezzano V, Nussbaum S, Burks AW. Induction of remission of idiopathic anaphylaxis with rituximab. J Allergy Clin Immunol. 2014;134:981-3.

\section{Submit your next manuscript to BioMed Central and take full advantage of:}

- Convenient online submission

- Thorough peer review

- No space constraints or color figure charges

- Immediate publication on acceptance

- Inclusion in PubMed, CAS, Scopus and Google Scholar

- Research which is freely available for redistribution

Submit your manuscript at www.biomedcentral.com/submit 